\title{
Uso de produtos florestais não madeireiros em comunidades da Flona Tapajós
}

\author{
Danielly Caroline Mileo GONÇALVES1*, João Ricardo Vasconcellos GAMA1, \\ Jéssica Ariana de Jesus CORRÊA ${ }^{1}$, Raimundo Cosme de OLIVEIRA JUNIOR² \\ ${ }^{1}$ Instituto de Biodiversidade e Floresta, Universidade Federal do Oeste do Pará, Santarém, PA, Brasil. \\ ${ }^{2}$ Centro de Pesquisa Agroflorestal da Amazônia Oriental, Empresa Brasileira de Pesquisa Agropecuária, Belém, PA, Brasil. \\ *E-mail: daniellycmg@gmail.com \\ (Orcid: 0000-0003-0521-115X; 0000-0002-3629-3437; 0000-0002-2691-6020; 0000-0002-2735-1746)
}

\begin{abstract}
Recebido em 05/01/2021; Aceito em 01/07/2021; Publicado em 14/07/2021.
RESUMO: O objetivo deste artigo é caracterizar o uso dos produtos florestais não madeireiros (PFNM) pelas populações ribeirinhas em comunidades na Flona Tapajós, compreendendo as questões relacionadas às principais espécies coletadas, seus usos e atribuição de valor aos produtos confeccionados. Foi realizado um Diagnóstico Rápido Rural (DRR) com os coletores de PFNMs, e entrevistas com um total de 10 artesãos. As espécies mais citadas foram: morototó, tento vermelho, tento amarelo, saboneteira, açaí, jutaí e lágrima de nossa senhora que são utilizadas na produção de artesanatos e biojóias; também se utiliza as fibras (buriti, tucumã e curuá) e as madeiras (coração de negro, itaúba, cedro, arara castanha e molongó). As biojóias variam de valor entre $R \$ 2,00$ a $R \$ 20,00$ e as peças ornamentais de madeira de $R \$ 10,00$ a $R \$ 300,00$. As principais vantagens de trabalhar com PFNM apontadas na entrevista são a facilidade de coletar sementes, o fato de ter demanda e gerar renda aos artesãos envolvidos. As dificuldades mencionadas são a coleta das sementes do morototó e paricá e o acesso as árvores na floresta. Jamaraquá, Maguari e São Domingos são exemplos bem-sucedidos de que os produtos oriundos da floresta têm mercado consolidado e são representação cultural e social dos povos da floresta.
\end{abstract}

Palavras-chave: artesanato; biojóias; população tradicional; Amazônia.

\section{Use of non-wooden forest products in the National Forest of Tapajós communities}

\begin{abstract}
The aim of this article is to characterize the use of non-timber forest products (NTFP) by riverine populations in communities in Flona Tapajós, including issues related to the main species collected, their uses and attribution of value to the manufactured products. the use of non-timber forest products (NTFP) by riverine populations in communities in Flona Tapajós, including issues related to the main species collected, their uses and attribution of value to the products made. A rapid rural appraisal (RRA) was conducted with community NTFP collectors, followed by interviews with the artisans, including a total of 10 people. The most cited species in the RRA were morototó, bead tree, tento amarelo, wingleaf soapberry, açaí palm, jutaí, and Job's tears, which are used to produce handicrafts and bio-jewels. In addition, buriti, tucumã, and curuá fiber and lapachillo, itaúba, cedar, arara castanha, and molongó wood were used. The price of bio-jewels varies from BRL 2 to 20, and of the wood ornamental pieces from BRL 10 to 300. The main advantages of working with NTFP highlighted in the interviews were that seed collection is easy, that there is demand, and that income is generated for community members. The difficulties mentioned were the collection and processing of morototó and paricá seed, and access to trees. Jamaraquá, Maguari, and São Domingos are successful examples of forest products that consolidated the market and are cultural and social representation of the forest peoples.

Keywords: handicrafts; bio-jewels; traditional population; Amazon.
\end{abstract}

\section{INTRODUÇÃO}

Os produtos florestais não madeireiros (PFNMs) são provenientes de florestas nativas, plantadas e de sistemas agroflorestais (PAES-DE-SOUSA et al., 2011). Das espécies vegetais podem ser usadas folhas, frutos, fibras, sementes, óleos, resinas, gomas, borrachas, cogumelos, entre outros (CALDERON, 2013). Outros autores consideram também o resíduo da madeira para produção de artesanato (SILVA, 2011; ANDRADE; LIMA, 2016).

Em termos econômicos, os PFNMs ainda não são expressivos, no entanto, para as populações tradicionais e extrativistas, esses produtos são imprescindíveis para sua sobrevivência (PAES-DE-SOUSA et al., 2011). Os PFNMs incrementam a renda dessas populações, promovendo, ao mesmo tempo, a conservação da floresta, já que a colheita dos produtos gera um mínimo de impacto ao funcionamento das florestas, e consequentemente manutenção dos recursos para as gerações futuras (IMPERADOR; WADT, 2014; GONÇALVES et al., 2019).

$\mathrm{Na}$ Amazônia, as populações tradicionais têm uma relação muito próxima com a floresta e seus produtos (SANTOS; COELHO-FERREIRA, 2012; CAMPOS et al., 2015; SHANLEY et al., 2015). Os antigos povos, que antes eram nômades, se fixavam em lugares provisórios em busca desses produtos e, com o passar do tempo, foram se 
estabelecendo nos locais onde se acumulavam sementes de várias espécies; criando assim um ecossistema antropogênico, ambientes ideais para sua fixação, portanto, moldando a floresta que se conhece hoje por meio da seleção de espécies úteis (SHANLEY et al., 2015).

Nesse contexto, a Floresta Nacional do Tapajós (Flona Tapajós) - uma Unidade de Conservação (UC) de Uso Sustentável, criada pelo Decreto n ${ }^{\circ} 73.684 / 1974$ e, segundo BRASIL (2000), tem como objetivo o uso sustentável dos recursos florestais e a pesquisa científica (SILVA et al., 2016). Nas comunidades inseridas na Flona Tapajós, a agricultura familiar é a principal atividade econômica, com plantio de mandioca (Manihot spp.), feijão (Phaseolus spp.) e plantas frutíferas (ICMBIO, 2017). Complementando a dieta alimentar, os comunitários praticam a pesca e a caça artesanal (ELIAS; SANTOS, 2016) e, para aumentar a renda das famílias, além do trabalho com ecoturismo (MOREIRA; BURNS, 2015), tem também, na coleta de produtos florestais não madeireiros, fonte de alimento, de plantas medicinais, fibras, óleos, sementes para artesanatos e outros produtos que fazem parte da realidade dessas comunidades. São produtos de valor não apenas econômico, mas de extrema importância cultural para as populações locais (ELIAS; SANTOS, 2016).

Os PFNMs são vistos como uma alternativa viável para o desenvolvimento das comunidades na Amazônia e, ao mesmo tempo, uma forma de conservação das florestas por ser uma atividade de baixo impacto. Portanto, o presente artigo tem como objetivo caracterizar o uso dos produtos florestais não madeireiros pelas populações ribeirinhas em comunidades na Flona Tapajós, compreendendo as questões relacionadas às espécies vegetais coletadas/extraídas, a transformação e atribuição de valor aos produtos oriundos dos PFNMs.

\section{MATERIAL E MÉTODOS}

\section{1. Área de estudo}

A área de estudo está na região Oeste do Pará, Brasil, localizada na unidade de conservação Floresta Nacional do Tapajós (Flona Tapajós), pertencente ao município de Belterra (Figura 1). O presente trabalho tem autorização para pesquisa científica do Sistema de Autorização e Informação da Biodiversidade - SISBIO com o n54874-3. A Flona Tapajós abrange uma área de aproximadamente 600.000 hectares e apresenta 1.050 famílias e, aproximadamente, 4 mil moradores, distribuídos em localidades ao longo da rodovia BR-163 (lotes com assentados do Incra, proprietários e posseiros), e em 23 comunidades e três aldeias indígenas da etnia Munduruku As comunidades estão localizadas as margens do Rio Tapajós, sendo elas: São Domingos, Maguari, Jamaraquá, Acaratinga, Jaguarari, Pedreira, Bom Jesus, Piquiatuba, Marituba, Nazaré, Bragança, Novo Marai, Marai, Pini, Tauari, Chibé, Takuara, Prainha I, Prainha II, Itapaiúna, Paraíso, Jutuarana, Itapuama, São Francisco das Chagas, São Francisco do Godinho e Uruará (ICMBIO, 2017).

As comunidades selecionadas para esse estudo foram: São Domingos, Maguari e Jamaraquá situadas ao norte da Flona Tapajós (Figura 1), no município de Belterra/PA. A vegetação é do tipo Floresta Ombrófila Densa de terra firme, com ocorrência de árvores de grande porte, lianas lenhosas, epífitas e palmeiras (ICMBIO, 2017). O clima é tropical úmido com temperatura média anual de $25^{\circ} \mathrm{C}$, classificação
Ami, pelo sistema de Köppen, com umidade relativa média de $86 \%$, com precipitação média anual em torno de 1.820 $\mathrm{mm}$, com o regime de chuvas apresentando uma variação grande durante $\mathrm{o}$ ano, com precipitação mais intensa ocorrendo nos meses de janeiro a maio (ALVARES et al., 2013). O relevo varia de plano a ondulado, com predomínio de Latossolo Amarelo (ITTO, 2004).

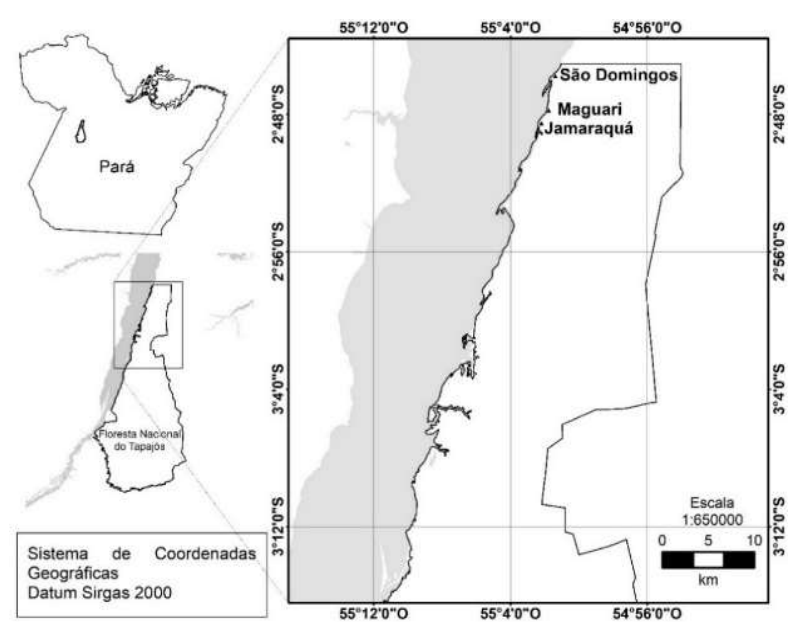

Figura 1. Localização das Comunidades Jamaraquá, Maguari e São Domingos na Floresta Nacional do Tapajós, Belterra, Pará, Brasil. Figure 1. Location of Jamaraquá, Maguari and São Domingos Communities in the Tapajós National Forest, Belterra, Pará, Brazil.

As pessoas residentes na Flona Tapajós provêm da miscigenação do povo indígena tapajônico, com migrantes nordestinos, que vieram trabalhar nos seringais e, em menor número, com povos africanos, trazidos como escravos pelos colonos portugueses (CROMBERG; GRECO, 2008).

\subsection{Coletas de dados}

A coleta de dados referente a caracterização do uso de PFNMs nas comunidades foi por meio de pesquisa participativa utilizando o Diagnóstico Rápido Rural - DRR (CHAMBERS, 2013).

Para a aplicação do DRR foram realizadas reuniões introdutórias com os coletores/artesãos, para explanar os objetivos da pesquisa (MENTON, 2003) e foi solicitada a participação dos mesmos na entrevista posterior com aqueles que trabalham com os PFNMs, momento em que os entrevistados assinaram o Termo de Consentimento Livre e Esclarecido. Como técnica de amostragem foi adotada a bola de neve (snowball), conforme Minayo et al. (2009).

Após o DRR, foi realizada uma entrevista em cada comunidade, com a participação de três artesãs na comunidade de Jamaraquá; seis artesãos na comunidade Maguari e uma artesão em São Domingos. utilizou-se perguntas estruturadas (sistemáticas) e perguntas não estruturadas (assistemáticas) (MINAYO et al., 2009), relacionadas ao produto extraído/manejado, produtos confeccionados, atribuição de valor aos produtos, dificuldades, vantagens e perspectivas futuras com o trabalho envolvendo PFNMs.

A sistematização e análise de dados teve caráter explicativo e descritivo, com os dados qualitativos sendo processados de modo dissertativo. Já os dados quantitativos foram organizados em tabelas e analisados por meio de estatística descritiva, com o auxílio da planilha eletrônica Excel 2010. 


\section{RESULTADOS}

\subsection{Coleta e produção de PFNMs}

Nas três comunidades os produtos mais coletados da floresta são as sementes arbóreas (Tabela 1), sendo as mais citadas: morototó (Schefflera morototoni (Aubl.) Maguire, Steyerm. \& Frodin), tento vermelho (Ormosia arborea L. I Adenanthera pavonina L.), tento amarelo (Ormosia excelsa Beth), saboneteira (Sapindus saponaria L.), açaí (Euterpe oleracea Mart.), jutaí (Hymenaea courbaril L.) e a planta herbácea lágrima de nossa senhora (Coix lacryma-jobi L.).

A produção com PNFMs pelos artesãos das três comunidades abrangem biojoias, manta FSA (Folha SemiArtefato) de látex, cestos e artesanatos de madeira.

$\mathrm{Na}$ comunidade Jamaraquá são 10 mulheres e suas famílias que utilizam as sementes florestais na produção de biojoias (Figura 2) e agregam a borracha beneficiada do látex de seringa nesses produtos.

Em Maguari são 14 famílias envolvidas com a produção da manta FSA (Folha Semi-Artefato), com seis famílias trabalhando com biojóias (Figura 2). Além das sementes, utilizam a palha de tucumã (Astrocaryum aculeatum G. Mey) e curuá (Ananas lucidus Miller) para fabricar as biojóias e cestarias. Outra atividade realizada por uma única família é o artesanato de animais em madeira para decoração e bancos (Figura 3). A madeira mais utilizada é o molongó (Lacmellea arborescens (Müll.Arg.) Markgr.), como cedro (Cedrela spp.), entre outras.

A família em São Domingos confecciona colares com sementes e madeira (resíduos), e com as fibras, principalmente de tucumã fazem cestas decorativas. As sementes mais utilizadas são: morototó, tento (vermelho e amarelo), saboneteira, jutaí e babaçu (Attalea speciosa Mart.). As madeiras utilizadas são: coração de negro (Swartz̧ia leiocalycina Benth), arara castanha (Joannesia heveoides Ducke) e itaúba (Mezilaurus itauba (Meissn.) Taub.).

Tabela 1. Produtos florestais não madeireiros coletados/extraídos nas comunidades de Jamaraquá, Maguari e São Domingos na Floresta Nacional do Tapajós, Belterra, Pará, Brasil.

Table 1. Non-timber forest products collected/extracted in the communities of Jamaraquá, Maguari and São Domingos, in the Tapajós National Forest, Belterra, Pará, Brazil.

\begin{tabular}{|c|c|}
\hline Comunidade & PFNM extraídos/coletados \\
\hline Jamaraquá & $\begin{array}{l}\text { Sementes (morototó, tento vermelho e amarelo, saboneteira, jutaí, coco, açaí1, tucumã }{ }^{1} \text {, lágrimas de nossa senhora }{ }^{2} \text {; } \\
\text { paxiúba-Socratea exorrbiza (Mart.) H.Wendl. } \\
\text { Látex da seringueira - Hevea brasiliensis M. Arg.); }\end{array}$ \\
\hline Maguari & $\begin{array}{l}\text { Sementes (morototó, tento vermelho e amarelo, saboneteira, jutaí, coco - Cocos nucifera L., açaí1 }{ }^{1} \text {, tucumã }{ }^{1} \text { - Astrocaryum } \\
\text { aculeatum G.Mey, lágrimas de nossa senhora }{ }^{2} \text {, flamboyant }{ }^{3} \text { - Delonix regia (Hook.) Raf., olho de boi - Dioclea violacea Mart. } \\
\text { ex Benth, cérebro de macaco - Sp, caracaxá ou jupati-Raphia taedigera Mart., Paricá-Schizolobium amazonicum Huber ex } \\
\text { Ducke); } \\
\text { Látex da seringueira } \\
\text { Fibra de tucumã } \\
\text { Fibra de buriti1 }^{1} \\
\text { Fibra de curuá } \\
\text { Madeiras brancas (molongó) } \\
\text { Madeiras e trocos (cedro, tapiriqueira) }\end{array}$ \\
\hline São Domingos & $\begin{array}{l}\text { Sementes (morototó, babaçu, açaí }{ }^{1} \text {, saboneteira }{ }^{3} \text { ) } \\
\text { Palha de tucumã } \\
\text { Madeira para confeccão de biojóias (coração de negro, itaúba e arara castanha) }\end{array}$ \\
\hline
\end{tabular}

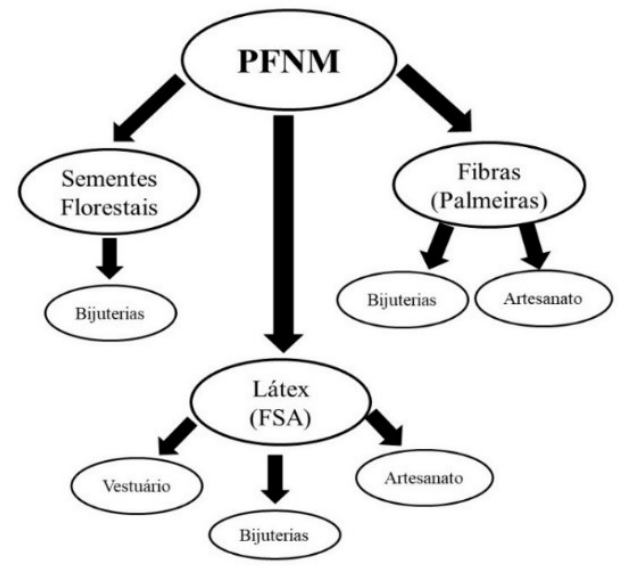

Figura 2. Fluxograma dos produtos oriundos dos PFNMs produzidos nas Comunidades de Jamaraquá, Maguari e São Domingos, Floresta Nacional do Tapajós, Belterra, Pará, Brasil.

Figure 2. Flowchart of products from the NTFPs produced in the Communities of Jamaraquá, Maguari and São Domingos, Tapajós National Forest. Belterra, Pará, Brazil.

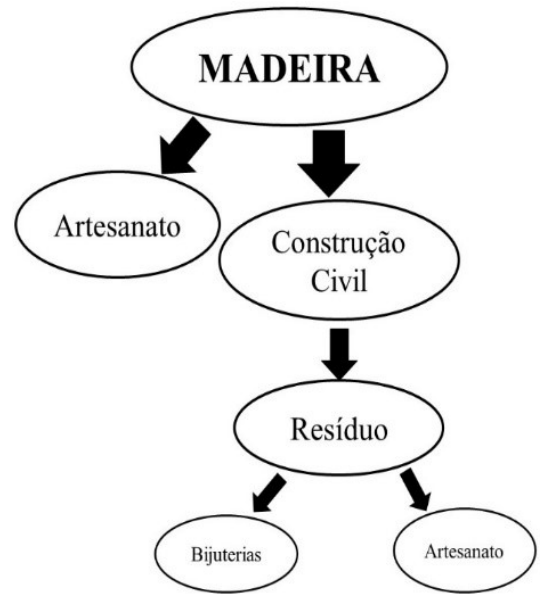

Figura 3. Fluxograma dos produtos oriundos da madeira produzidos nas Comunidades de Jamaraquá, Maguari e São Domingos, Floresta Nacional do Tapajós, Belterra, Pará, Brasil.

Figure 3. Flowchart of wood products produced in the communities of Jamaraquá, Maguari and São Domingos, Tapajós National Forest, Belterra, Pará, Brazil. 


\subsection{Valorações dos produtos oriundos de PFNMs}

Na comunidade Jamaraquá a valoração dos produtos é feita de forma empírica, por consenso entre as mulheres da comunidade. $\mathrm{Na}$ loja, os produtos vendidos são anotados em um caderno, sendo feita a discriminação do tipo de produto e de quem o produziu. Os preços médios variam de $\mathrm{R} \$ 7,50$ a $\mathrm{R} \$ 18,00$ (Figura 4) sendo os principais produtos produzidos colares, brincos e pulseiras.

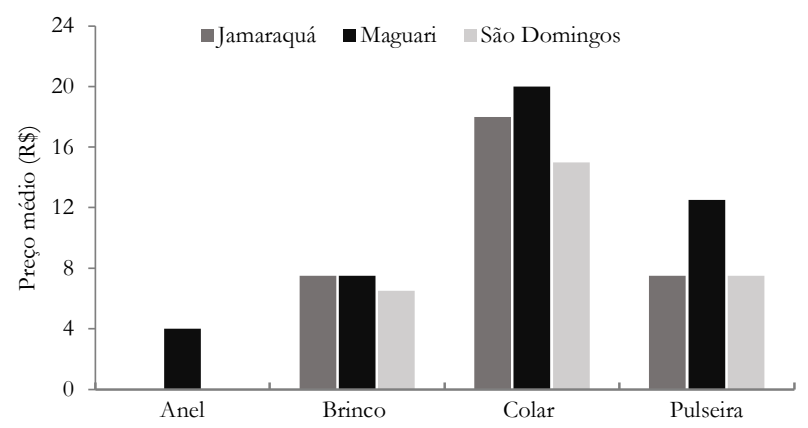

Figura 4. Preço médio das biojóias (1. Anel, 2. Brincos, 3. Colares, 4. Pulseiras) produzidas nas Comunidades de Jamaraquá (Preto), Maguari (Cinza escuro) e São Domingos (Cinza claro), Floresta Nacional do Tapajós, Belterra, Pará, Brasil.

Figure 4. Average price of biojewels (1. Ring, 2. Earrings, 3. Necklaces, 4. Bracelets) produced in the communities of Jamaraqua (Black), Maguari (Dark gray) and São Domingos (Light gray), in Tapajós National Forest, Belterra, Pará, Brazil.

Em Maguari os grupos familiares definem os valores de cada peça, dentre elas, colares, pulseira, brincos e anéis, com preços médios que variam de $\mathrm{R} \$ 4,00$ a $\mathrm{R} \$ 20,00$ reais (Figura 4). A maioria tem um registro da venda de suas peças anotado em um caderno.

Os animais entalhados são produzidos por apenas um artesão que trabalha sozinho. Os valores dos artefatos decorativos variam de acordo com o tamanho e o grau de dificuldade de produção. O artesão atribuiu dois tamanhos (pequeno e grande), variando de $\mathrm{R} \$ 10,00$ a $\mathrm{R} \$ 20,00$, os pequenos, e, $\mathrm{R} \$ 200,00$ a $\mathrm{R} \$ 300,00$, as peças maiores.

$\mathrm{Na}$ comunidade de São Domingo os valores dos produtos produzidos com PFNMs variam de $\mathrm{R} \$ 6,50$ a $\mathrm{R} \$ 15,00$ reais (Figura 4). As peças vendidas não são registradas pelos artesãos, dessa forma, não fazem o controle da quantidade e nem discriminam o que é comercializado.

\subsection{Vantagens e dificuldades na coleta e produção de PFNMs}

As principais vantagens apontadas na pesquisa foram à localização de coleta das sementes (29\%), seguido da boa aceitação do mercado (venda) $(22 \%)$ e a geração de renda para os comunitários (21\%) (Figura 5).

Dentre as dificuldades mencionadas pelos entrevistados, as que mais foram citadas são o acesso as árvores da floresta $(29 \%)$, a colheita das sementes $(23 \%)$, e a coleta de sementes no período chuvoso (12\%) (Figura 6).

Algumas sementes são difíceis de coletar, seja pela altura da árvore, ou pela distância a ser percorrida. A coleta das sementes ocorre uma vez ao ano, em função do período de frutificação de cada espécie.

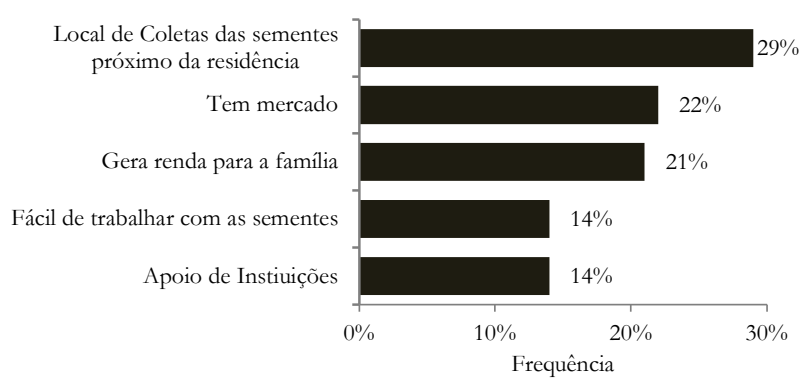

Figura 5. Principais vantagens no manejo de PFNMs e seus produtos nas comunidades de Jamaraquá, Maguari e São Domingos, Floresta Nacional do Tapajós, Belterra, Pará, Brasil.

Figure 5. Main advantages in the management of NTFPs and their products in the communities of Jamaraquá, Maguari and São Domingos, Tapajós National Forest, Belterra, Pará, Brazil

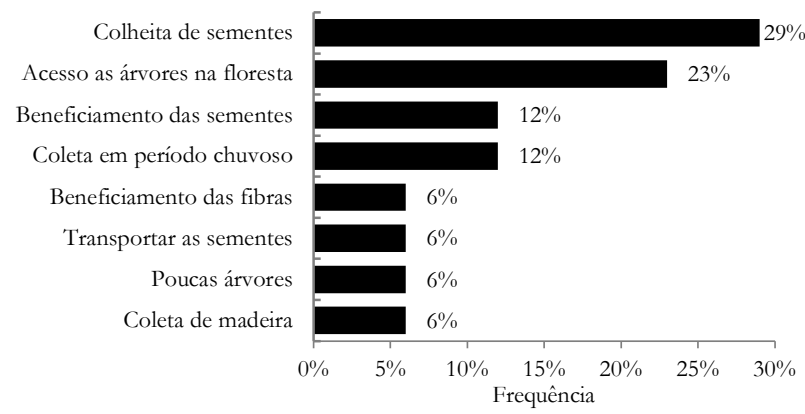

Figura 6. Principais dificuldades no manejo de PFNMs e seus produtos nas comunidades de Jamaraquá, Maguari e São Domingos, Floresta Nacional do Tapajós, Belterra, Pará, Brasil.

Figure 6. Main difficulties in the management of NTFPs and their products in the communities of Jamaraquá, Maguari and São Domingos, Tapajós National Forest, Belterra, Pará, Brazil.

\section{DISCUSSÃO}

Os produtos mais coletados da floresta são as sementes arbórea. A maioria é coletada na floresta nos entornos das comunidades. Na comunidade Maguari, os comunitários coletam sementes para produção artesanal em locais de floresta secundária (GONÇALVES et al., 2019).

Algumas espécies foram domesticadas no quintal das residências dos artesãos, como é o caso da saboneteira. Outros, como açaí e a lágrima de nossa senhora, que são utilizadas na confecção do artesanato local são compradas em lojas de Santarém (açaî) e Manaus (lágrimas de nossa senhora).

As principais atividades desenvolvidas com os PFNMs Em Jamaraquá, Maguari e São Domingos estão relacionadas a produção de biojoias e outros artesanatos, que por sua vez, ganharam mais notoriedade através do turismo ecológico nas comunidades envolvidas, além de impulsionar a participação das mulheres no papel principal dessa atividade.

Os trabalhos que abordam o uso de PFNMs na produção de artesanato por comunidades tradicionais (SILVA et al., 2014; SANTOS; SILVA et al., 2016; LOPES; SCHEIRHOLT, 2018), descrevem que em sua maioria a produção de biojoias e outros artefatos é realizado por mulheres, assim como nas comunidades do presente estudo.

As mulheres, por exemplo, têm a função de coletar as sementes (sementes do chão da floresta), selecioná-las, cozêlas e manufaturá-las para a comercialização posterior. Já a função dos homens, são as atividades mais pesadas, em princípio é a coleta de semente em que precise subir nas árvores, portar facões, cortar galhos de árvores ou arbustos 
que obstruam a trilha, matar animais peçonhentos, entre outros (SILVA et al., 2014).

$\mathrm{Na}$ comunidade de Jamaraquá, os produtos gerados pelas sementes são confeccionados por um grupo de mulheres que produzem as biojoias e os artesanatos. A confecção ocorre na casa das artesãs, que posteriormente são levados para um local comunitário para serem expostos aos visitantes

As mulheres artesãs de Jamaraquá, destacaram a habilidade de coleta de sementes, para a confecção de biojoias, utilizando seus conhecimentos empírico sobre o uso do ecossistema florestal, para identificar as sementes mais resistentes, onde encontrar, em qual período do ano, período de perecibilidade, dentre outras atribuições (SILVA et al., 2014). No presente estudo, as mulheres são a maioria nas atividades envolvendo PFNMs, principalmente no artesanato. Porém, foi evidenciada a participação dos homens como o descobridor de novos pontos de coleta de sementes.

A relação das mulheres e os PFNMs é baseado historicamente na cultura de alguns povos em coletar alimentos, combustíveis e matéria-prima para artesanatos como uma atividade atribuída ao gênero feminino. Em contrapartida, o homem tem a função de coletar produtos utilizados com menos frequência, como a madeira para construção de casas, postes e cercas, além de outros serviços considerados pesados como a caça (Shackleton et al., 2011).

As mulheres em Jamaraquá não coletam as sementes na floresta, é um trabalho dos homens (esposos e filhos) que vão à floresta, no ecossistema de terra firme, em busca de morototó, tento vermelho, paxiúba (Socratea exorrbiza (Mart.) H.Wendl.) e, no ecossistema de igapó, colhem o tento amarelo.

Assim também acontece em Maguari, as famílias envolvidas nessa atividade têm suas tarefas bem divididas. Os homens coletam as sementes, e as mulheres fazem o beneficiamento e a montagem das biojoias, assim como em São Domingos. As espécies coletadas são: jutaí, saboneteira, morototó, tento vermelho, seringa, caracaxá ou jupati, cérebro de macaco e o flamboyant são coletados na floresta, enquanto o tento amarelo é coletado na praia, além da extração do látex para fazer as mantas de FSA.

Em Maguari, a coleta de semente é destinada à montagem de biojoias, e a madeira, para fabricação de animais entalhados usados em decoração. $\mathrm{Na}$ produção das biojoias cada artesão vende sua produção na sua residência, mas a confecção é feita em pequenos grupos de mulheres, que se reúnem na casa de uma artesã, normalmente com a matriarca da família, para a montagem.

A produção das biojoias em Maguari foi impulsionada pelo crescente turismo na comunidade em que os turistas ficam hospedados nas casas dos comunitários. Além da hospedagem, a venda de artesanato e biojoias foram incrementadas para que os visitantes pudessem levar uma lembrança do local. A produção de biojoias na comunidade visa a comercialização em escala local para os visitantes da comunidade (SILVA et al., 2014; SILVA et al., 2016).

Quanto a comunidade de São Domingos a produção familiar gira em torno de cestas, biojoias e artesanato em madeira, mas sua principal renda advém do ecoturismo. A produção do artesanato e da biojoias já eram praticados pelo núcleo familiar, no entanto, para uso pessoal. Com o vislumbre de agregar valor cultural para que os turistas pudessem associar algo da comunidade a cultura local, além da possibilidade de renda extra para a subsistência familiar, começaram a produzir artesanatos e biojoias para exposição e venda aos turistas.

O turismo alicerçado nas comunidades vem beneficiando as populações tradicionais nas três comunidades do presente estudo. O Plano de Manejo da Unidade prevê e incentiva esse tipo de atividade, tanto que já foram oferecidos cursos de capacitação aos comunitários, incluindo cursos destinados para a melhoria das técnicas de produção de biojoias, investimentos na infraestrutura e implantação de trilhas. No entanto, vínculos precisam ser restabelecidos e novas parcerias feitas para que esse alvo seja alcançado (MOREIRA; BURNS, 2015).

A produção de biojoias, utilizando os recursos da natureza, ao mesmo tempo promovem a valorização da cultura e mão de obra local, contribui significativamente para o desenvolvimento sustentável como um todo (GONDIM, 2015). A produção e a coleta de sementes da floresta nas Comunidades de São Domingos, Maguari e Jamaraquá é uma atividade social direcionada à conservação da floresta, por não retirar recursos além de suas necessidades e, dessa forma, colaborar com o manejo tradicional e usufruto dos recursos disponíveis no entorno das comunidades (SILVA et al., 2016).

Muitos povos indígenas já utilizavam sementes na confecção de suas indumentárias de rituais, atualmente esses artefatos são vendidos nas cidades por várias etnias indígenas (ZEA, 2006; CARVALHO, 2015). A etnias Wai-Wai, do território indígena (T.I), Nhamundá-Mapuerá, em Oriximiná-PA, confeccionam biojoias principalmente das sementes de morototó que são coletadas no entorno de suas habitações. Essas sementes são beneficiadas e tingidas para a elaboração de diversas peças (ZEA, 2006).

A etnia Saterê-Mawé, localizada no médio Rio Amazonas, denominada T.I. Andirá-Marau, na fronteira dos Estados do Amazonas e do Pará, também utilizam as sementes de diversas espécies, a saber: jarina (Phytelephas macrocarpa Ruiz \& Pav.), murumuru (Astrocaryum murumuru Mart.), ingarana (Abarema jupunba Barneby \& Grimes), morototó, puçá (Mouriri apiranga Spruce ex Triana) e o tucumã (CARVALHO, 2015).

A produção das biojoias nas comunidades da Flona Tapajós tornou-se um complemento de renda para muitas famílias. Porém, deve ser realizada de maneira sustentável, sem agressão ao meio ambiente e sem a geração de muitos resíduos durante as etapas de produção. Esses processos fortalecem as culturas regionais, pois os materiais para confecção das biojoias são encontrados nas florestas, refletindo os valores sociais, culturais e econômicos de cada parte do país (GONDIM, 2015).

A atribuição de valor aos produtos mostra que os artesãos se preocupam com a qualidade das peças produzidas e, dessa forma, eles compreendem que o consumidor vai ter uma melhor aceitação do produto (SEBRAE, 2014; SILVA et al., 2014; SILVA et al., 2016). Entretanto, alguns aspectos relacionados ao controle do que é vendido, ou qual peça tem maior aceitação, ainda não é percebida como importante, assim, não se tem uma ideia de qual item tem maior aprovação por parte dos compradores que visitam as comunidades. Em Jamaraquá e Maguari a maioria dos artesãos possui controle do que é vendido, mostrando uma maior organização, em relação aos de São Domingos, que não possuem controle na produção e venda de suas peças.

Os critérios para atribuir valor monetário às sementes são a dureza, dificuldade para encontrá-las na floresta e valor estético. Quanto mais duras, as sementes oferecem mais 
resistência ao desgaste ao longo do tempo; quanto mais difíceis de serem encontradas, mas incidirá no seu valor de troca final. Além disso, a estética é determinante para o valor final da peça.

Esses critérios fazem com que se agregue valor as peças produzidas pelos comunitários, e assim podem corar um maior. Em Jamaraquá, 15\% das famílias artesãs pagam suas despesas mensais somente com a produção de biojoias, por isso é considerada como complementação, as principais fontes de renda são bolsa governamental e turismo (SANTOS et al., 2018). Análogo ao que acontece nas comunidades em estudo, outras comunidades inseridas na Amazônia, executam manejo similar à extração de PFNMs para fins de subsistência e geração de renda (AMARAL et al., 2007; AHENKAN; BOON, 2010; PEREIRA et al., 2016).

Essa geração de renda complementar é possível graças à facilidade de encontrar áreas para coleta de semente, pois ocorrem em florestas próximas as residências, apresentando facilidade de obter a matéria-prima para produção dos artesanatos e biojoias. Exemplo disso, é a semente do tento amarelo, que se localiza em florestas de igapó próximas das casas dos comunitários. Além disso, domesticaram as espécies saboneteira e flamboyant, plantando essas árvores em seus quintais, facilitando ainda mais a obtenção das sementes.

A facilidade de comercialização apontada como vantagem nos resultados, ocorre devido a venda direta dos artesanatos e biojoias produzidos nas comunidades. Para os comunitários houve uma melhoria com o advento do ecoturismo nas comunidades, onde isso impulsionou as comunidades a investir no mercado de biojoias.

Para o mercado local, em Jamaraquá criou-se uma loja para a venda dos artesanatos produzidos na comunidade, além disso há uma mini fábrica artesanal para o beneficiamento da manta de FSA em anexo à loja. A comunidade verticaliza a produção de borracha por meio da confecção de FSA e Folha Defumada Líquida (FDL) (GAMA et al., 2017).

Em Maguari, o mercado funciona na casa de uma das artesãs, em um expositor adaptado, em que os turistas que visitam a comunidade, visualizam e assim compram os produtos. Da mesma forma, os artesãos de São Domingos, tem suas em suas casas as peças expostas para os visitantes e hospedes.

Com a produção e venda dos artesanatos e biojoias, a renda dessas famílias aumentou, aproximadamente 24\%, principalmente nos meses de julho e janeiro (Silva et at. 2016) um ponto positivo no manejo de PFNMs nessas comunidades. Em destaque, as mulheres (artesãs) que antes não possuíam renda, apenas executavam trabalhos domésticos, viram uma oportunidade de um ofício para agregar a renda familiar.

As artesãs de Jamaraquá relatam que com o dinheiro proveniente da venda das biojoias, conseguem ter certa independência financeira dos maridos, conseguindo comprar tanto material para a produção das biojoias e também produtos para seu uso pessoal ou para a casa.

Os artesãos de Maguari acreditam que o lucro das vendas dos artesanatos e biojoias melhorou a renda das famílias envolvidas. Da mesma maneira a família de São Domingos acredita que a renda extra aumentou o poder de compra, tanto para compra de bens e alimentação, como também para material para produção das biojoias.

O apoio das instituições como Instituto Chico Mendes de
Conservação da Biodiversidade (ICMBIO), Ministério da Educação, por meio do Programa Nacional de Acesso ao Ensino Técnico e Emprego (Pronatec) e a Empresa de Assistência Técnica e Extensão Rural do Estado do Pará (Emater) foram mencionados como agentes colaboradores na produção de artesanatos e biojoias.

O ICMBIO promove o desenvolvimento socioambiental pela concessão de áreas destinadas ao manejo de recursos naturais. O Pronatec capacitou os artesãos na produção de biojoias, possibilitando o melhoramento das técnicas e atribuição de valor as peças produzidas. A Emater promove assistência técnica a agricultura familiar realizada pelas populações tradicionais, em parceria com a Cooperativa Mista da Flona Tapajós (Coomflona) por meio do Termo de Reciprocidade (ICMBIO, 2017). Outra vantagem atribuída é a facilidade em trabalhar com sementes, o manuseio e as técnicas de beneficiamento são conhecidos pelos artesãos, pois foram repassados pelos antecessores, que antes produziam apenas para seu próprio uso.

Sobre as dificuldades no manejo de PFNMs a coleta de sementes foi uma das que mais se destacaram, em especial, a coleta das sementes de morototó, tento vermelho e paricá. Cada espécie citada apresenta um motivo adverso. O morototó e o paricá são árvores altas e para a coleta de suas sementes é preciso subir ou derrubá-las para conseguir as sementes. O tento vermelho possui sementes contidas em vagens e, quando maduras, essas vagens se abrem e despejam as sementes em diferentes distâncias e, com isso, achar as sementes no chão da floresta se torna uma tarefa demorada para a coleta da quantidade necessária de sementes.

Como a maioria das sementes é coletada na floresta, a outra dificuldade relacionada é a coleta em grandes distâncias, já que as árvores se encontram dispersas, com isso, os coletores ficam longas horas caminhando pela floresta em busca de sementes adequadas, ou seja, sementes não danificadas, sem parasitismo ou fungos. A coleta em período chuvoso também impede a chegada em determinados pontos da floresta, pois algumas árvores se encontram em áreas distantes e de difícil acesso, além disso, algumas sementes podem ter sua qualidade afetada por conta do contato com a umidade do solo, podendo ser degradada por insetos ou infectada por fungos. Assim como a coleta de madeira, em especial, o molongó que tem que ser derrubado com técnica própria para não danificar sua qualidade.

Outro problema é o transporte da semente, como eles coletam para o ano todo, são grandes quantidades de semente a serem levadas até suas casas, tornando o trabalho pesado e cansativo, pois o percurso é feito todo a pé. A espécie saboneteira possuem poucas árvores e dessa forma, não é possível coletar uma quantidade suficiente de sementes, sendo necessário ir a outros locais para sua coleta ou até mesmo comprar de outras comunidades.

O beneficiamento das sementes também foi citado como dificuldade na comunidade de Maguari, pois muitas delas exigem que passe por um processo para retirada da polpa dos frutos, da seleção das sementes mais bonitas, depois são perfuradas, para que assim, sejam usadas na produção de biojoias. Algumas delas precisam ser fervidas antes de serem usadas, como a saboneteira e o morototó.

Apesar das dificuldades existentes na coleta e manejo de PFNMs, todos os atores em questão, sejam na coleta, como na produção dos artesanatos e biojoias, acreditam que essa atividade será por muito tempo valorizada, principalmente se houver investimento em aperfeiçoamento nas técnicas de 
produção, assim como, no melhor aproveitamento da matéria-prima, por meio do manejo adequado a cada tipo de recursos (PEREIRA et al., 2016). Portanto, os artesãos e os coletores têm a consciência de suas limitações atuais, em termos de uso de recursos florestais, e esperam que, no futuro, suas atividades tenham uma valorização $e$ reconhecimento por parte das instituições públicas, dos visitantes e frequentadores da $\mathrm{UC}$, e que o ecoturismo aumente as oportunidades e expansão da produção de biojoias e artesanatos.

\section{CONCLUSÕES}

A riqueza de PFNMs na Amazônia tem sido fonte de renda para comunidades que utilizam os recursos da floresta, ou de seus arredores, como matéria prima para a confecção de artesanato e biojoias. Um exemplo são as sementes de morototó que são bastantes utilizadas nas comunidades da Flona do Tapajós, especialmente na composição das biojoias. Esses produtos têm sido divulgados e vendidos através do turismo de base comunitária onde o comercio funciona de forma local. Embora os recursos estejam disponíveis na floresta, existem dificuldades enfrentadas pela atividade, como a capacitação comunitária para gerir melhor os recursos. Os produtos oriundos da floresta são valorizados por serem uma representação cultural e social dos povos da floresta, além de ser uma atividade geradora de renda. Por isso, deve-se haver maior incentivo para o manejo, principalmente uma maior organização, seja por meio de associações ou cooperativas de artesãos para melhorar técnicas de coletas, beneficiamentos e produções mais eficientes e menos danosas a floresta, como também buscar investimentos para o desenvolvimento da atividade e das comunidades.

\section{AGRADECIMENTOS}

A pesquisa foi apoiada pela Universidade Federal do Oeste do Pará (UFOPA), Programa de Pós-Graduação em Sociedade, Natureza e Desenvolvimento (PPGSND), e pela Fundação Amazônia de Amparo a Estudos e Pesquisas (FAPESPA) pela bolsa de fomento das autoras do presente estudo.

\section{REFERÊNCIAS}

AHENKAN, A.; BOON, E. Assessing the impact of forest policies and strategies on promoting the development of non-timber forest products in Ghana. Journal of Biodiversity, v. 1, n. 2, p. 85-102, 2010.

ALVARES, C. A.; STAPE, J. L.; SENTELHAS, P. C.; MORAES, G.; LEONARDO, J.; SPAROVEK, G. Koppen's climate classification map for Brasil. Meteorologische Zeitschrift, Berlin, v. 22, n. 6, p. 711728, 2013. DOI: $10.1127 / 0941-2948 / 2013 / 0507$

AMARAL, P.; AMARAL NETO, M.; NAVA, F. R.; FERNANDEZ, K. Manejo Florestal Comunitário na Amazônia Brasileira: avanços e perspectivas para a conservação florestal. Brasília: Serviço Florestal Brasileiro-SFB, 2007, 20p. Disponível em: http://www.florestal.gov.br/documentos/publicacoes/ 1685-manejo-florestal-comunitario-na-amazoniabrasileira/file. Acesso em: jun.2019.

ANDRADE, F. A. V.; LIMA, V. T. de. Artesão e o artesanato em madeira no Município de Parintins - AM sob a ótica da sustentabilidade. Revista Contribuciones a las Ciencias Sociales, Málaga, p.1-6, 2016.

BRASIL. Lei $\mathbf{n}^{\circ} \mathbf{9 . 9 8 5}$, de 18 de julho de 2000. Institui Sistema Nacional de Unidades de Conservação da Natureza - SNUC, estabelece critérios e normas para a criação, implantação e gestão das unidades de conservação. Brasília: DOU de 19/07/ 2000.

CALDERON, R. A. Mercado de Produtos Florestais Não Madeireiros na Amazônia brasileira. 84f. 2013. Tese (Doutorado em Ciências Florestais) - Universidade de Brasília, Brasília-DF, 2013.

CAMPOS, J. de A.; FONSECA, S. R. P. da; MENESES, M. C. de; HAMADA, M. O. de S. Etnobotânica de produtos florestais não madeireiros em Comunidade da Reserva Extrativista Verde para Sempre, Porto de Moz, Pará. Enciclopédia Biosfera, Goiânia, v. 11, n. 21, p. 10591067, 2015.

CARVALHO, J. M. de. Ritual da tucandeira da etnia Sateré-Mawé: língua, memória e tradição cultural. 153f. 2015. Dissertação (Mestrado em Letras e Artes) Universidade Estadual do Amazonas, 2015.

CHAMBERS, R. Rural Development: Putting the last first. London and New York: Routledge, 2013. 198p.

CROMBERG, M.; GRECO, T. M. Estratégias de Adaptação das comunidades na Floresta Nacional do Tapajós. Escola Superior de Agricultura Luiz de Queiroz, p. 1-19, 2008. Disponível em: https://projects.ncsu.edu/project/amazonia/brazil_pro j/Result/Greco_Cromberg_tapajos.pdf

ELIAS, G. A.; SANTTOS, R. dos. Produtos florestais não madeireiros e valor potencial de exploração sustentável da Floresta Atlântica no sul de Santa Catarina. Ciência Florestal, Santa Maria, v. 26, n. 1, p. 249-262, 2016. DOI: http://dx.doi.org/10.5902/1980509821117

GAMA, J. R. V.; VIEIRA, D. S.; SANTOS, S. S. dos; SANTOS, M. R. G. Potencial de produção dos seringais de Jamaraquá, estado do Pará. Advances in Forestry Science, Cuiabá, v. 4, n. 1, p. 77-82, 2017. DOI: $10.34062 /$ afs.v4i1.4152

GONÇALVES, D. C. M.; CORRÊA, J. J.; GAMA, J. R. V.; OLIVEIRA JÚNIOR, R. C. Análise da vegetação secundária em unidades de conservação: o uso de recursos florestais por comunidades tradicionais. Nature and Conservation, Aracajú, v. 12, n. 1, p. 1-9, 2019. DOI: https://doi.org/10.6008/CBPC23182881.2019.001.0001

GONDIM, N. D. Diagnóstico preliminar do perfil do comércio virtual de biojóias. In: Prêmio Serviço Florestal Brasileiro em estudos de economia e mercado florestal, II, 2015. 74p. Disponível em: https://www.florestal.gov.br/documentos/informacoes -florestais/premio-sfb/ii-premio/monografias-iipremio/graduando-1/576-ganhador-1-lugar-graduandomonografia/file

ICMBIO - Instituto Chico Mendes de Conservação da Biodiversidade. A Floresta Nacional do Tapajós, 2017. Disponível

em: https://www.icmbio.gov.br/flonatapajos/.

IMPERADOR, A. M.; WADT, L. H. O. Certificação de produtos florestais não madeireiros na perspectiva mercadológica de associações extrativistas no Estado do Acre. Holos, Natal, v. 30, n. 1, p. 126-135, 2014.

ITTO - International Tropical Timber Organization. Projeto ITTO PD 68/89 REV 1 (F): Manejo da Floresta

Nativa, Sinop, v. 9, n. 3, p. 302-309, mai./jun. 2021. 
Nacional do Tapajós para a produção sustentada de madeira industrial. Santarém, IBAMA/ITTO, 2004. $580 \mathrm{p}$.

LOPES, J. R.; SCHIERHOLT, A. F. P. Produção de biojóias no Norte do Brasil: Análise dos impactos institucionais, ambientais e de mercado em redes de sustentabilidade locais. Revista InterEspaço, Grajaú, v. 4, n. 14, p. 155173, 2018. DOI: http://dx.doi.org/10.18764/24466549.v4n12p155-173

MENTON, M. C. Effects of logging on non-timber forest product extraction in the Brazilian Amazon: community perceptions of change. International Forestry Review, v. 5 , n. 2, p. 97-105, 2003.

MINAYO, M. C. S. (Org.). Pesquisa Social. Teoria, método e criatividade. 28 ed. Petrópolis: Vozes, 2009. 80p.

MOREIRA, J. C.; BURNS, R. Turismo, manejo de uso público e a percepção dos visitantes: coleta de dados na Floresta Nacional do Tapajós (Pará). In: Congresso Brasileiro de Unidades de Conservação, VIII, 2015. Conference Paper... Curitiba: Fundação Grupo Boticário, 2015. 9p.

PAES-DE-SOUSA, M.; SILVA, T. N. da; PEDROZO, E. A.; SOUZA FILHO T. A. de. O Produto Florestal Não Madeirável (PFNM) amazônico açaí nativo: proposição de uma organização social baseada na lógica de cadeia e rede para potencializar a exploração local. Revista de Administração e Negócios da Amazônia, Porto Velho, v. 3, n. 2, p. 44-57, 2011.

PEREIRA, C. M. de S.; ASSIS, W. S. de; SÁ, T. D. de A. Extrativismo de produtos florestais não madeireiros na Amazônia: Conjuntura, políticas públicas e experiências. Amazônia: Ciência \& Desenvolvimento, Belém, v. 13, n. 23, p. 53-78, jul./dez. 2016.

SANTOS, K. M. P. dos; SILVA, R. J. N. da. O uso dos recursos naturais do cerrado para produção artesanal: um estudo de caso entre os índios Krahô. Revista Nera, Presidente Prudente, v. 33, n. 1, p. 20-46, 2016. DOI: https://doi.org/10.47946/rnera.v0i33.3109

SANTOS, M. F.; COSTA, D. L.; GAMA, J. R. V.; SOUSA, I. R. L.; FREITAS, B. B. Produção de biojóias e geração de renda de artesãs na comunidade Jamaraquá, Belterra, Pará. Cadernos de Agroecologia, v. 13, n. 1, p. 6-11, 2018. Disponível em: http://cadernos.abaagroecologia.org.br/index.php/cadernos/article/view/5 $24 / 883$

SANTOS, R. da S.; COELHO-FERREIRA, M. Estudo etnobotânico de Mauritia flexuosa L. f. (Arecaceae) em comunidades ribeirinhas do Município de Abaetetuba, Pará, Brasil. Acta Amazonica, Manaus, v. 42, n. 1, p. 1 10, 2012. DOI: https://doi.org/10.1590/S004459672012000100001
SARLO, H. B. Influência das fases da lua, da época de cortes e das espécies de bambussobre o ataque de Dinoderus minutus (Fabr.) (Coleoptera: Bostrichidae). 63f. 2000. Dissertação (Mestrado em Engenharia Florestal) - Universidade Federal de Viçosa, Viçosa, 2000.

SARMENTO, F. Design para a sustentabilidade na Floresta Nacional do Tapajós. In: Seminário de Pesquisas Científicas da Floresta Nacional do Tapajós, II. Anais... Santarém: ICMBio, 2014. p. 111-126. Disponível em: https://www.icmbio.gov.br/flonatapajos/images/storie s/destaques/anais_II_seminario_de_pesquisas.pdf

SEBRAE_Serviço Brasileiro de Apoio às Micro e Pequenas Empresas. Manejo sustentável da matéria-prima para o artesanato. Boletim de resposta técnica, 2014. 7p.

SHACKLETON, S.; PAUMGARTEN, F.; KASSA, H.; HUSSELMAN, M.; ZIDA, M. Opportunities for enhancing poor women's socio-economic empowerment in the value chains of three African non-timber forest products (NTFPs). International Forestry Review, v. 13, n. 2, p.136-151, 2011.

SHANLEY, P.; PIERCE, A. R.; LAIRD, S. A.; BIMMQÜIST, C. L.; GUARIGUATA, M. R. From lifelines to livelihoods: non-timber forest products into the twenty-first century. In: Tropical Forestry Handbook, 2015. p. 1-50. DOI: https://doi.org/10.1007/978-3-642-41554-8_209-1

SILVA, L. V. M. da. A produção de artesanatos pela Avive como uma proposta de design sustentável. 2011. 124. Dissertação (Mestrado em Ciências do Ambiente) Universidade Federal do Amazonas, Manaus-AM, 2011.

SILVA, M. de A.; NEVES, R. J.; NEVES, S. M. A. da S. Possibilidades de incorporação do processamento do cumbaru do assentamento Facão, Furna São José, na cadeia produtiva do turismo rural: estudo de caso na fronteira Brasil/Bolívia. Interações, Campo Grande, v. 17, n. 4, p. 591-605, out./dez. 2016.

SILVA, R. E. da; BONFIM, F. da; GARCIA, M. N. Coletoras de sementes do Tapajós: mulheres, saberes práticos, relações de gênero e a floresta saberes práticos, relações de gênero e a floresta. Revista Vivência, Natal, v. 43, p. 85-95, 2014.

SILVA, R. E. da; SOUZA, R. R.; BONFIM, F. S. A extração do látex e a coleta de sementes em comunidades da FLONA Tapajós: bases empíricas para discussão da racionalidade ambiental. Gaia Scientia, João Pessoa, Edição Especial, v. 10, n. 1, p. 126-132, 2016.

ZEA, E. S. 'Waiwai' Povos Indígenas do Brasil. São Paulo: Instituto Socioambiental, 2006. Disponível em: < https://pib.socioambiental.org/pt/Povo:Waiwai>. Acesso em: 24 de agosto de 2018. 